\title{
NOTAS SOBRE UN TEXTO DE CHARLES HORTON COOLEY
}

\author{
Charles Horton Cooley \\ "Democracy and Distintion" en Social Organization. \\ A Study of the Larger Mind \\ (Nueva York, Schocken Brooks, 1962)
}

El texto que aquí presentamos, titulado «Democracy and Distinction», es el capítulo 15 de la obra de Charles Horton Cooley (1864-1929) Social Organization. A Study of the Larger Mind, publicada en 1909.

El interés que tiene este texto para los científicos sociales actuales se sitúa en una gama bastante amplia de horizontes.

Cooley es un gran desconocido en la cultura sociológica europea en general y española en particular, a pesar de ser uno de los principales productores ${ }^{1}$ de los conceptos de grupo primario, cuyo interés analítico es grande, y del yo del espejo, cuyo interés se ha redoblado, con la vigorización de los enfoques subjetivistas a partir de la crisis de la Sociología en los años sesenta. Lewis A. Coser nos presenta a Cooley como un «sociólogo de butacón» y nos lo pone como ejemplo de cómo «es posible ensanchar las fronteras de las ciencias sociales permaneciendo sentado en el butacón propio»². Su principal producción intelectual está contenida en cuatro libros: Human

' Empleamos esta expresión tan ambigua de «uno de los principales productores» como consecuencia de la lectura de los comentarios de Merton sobre la génesis de los conceptos, donde precisamente toma como ejemplos de genealogía de conceptos las de los conceptos de grupo primario y de «self-espejo» (R. K. MERTon, Teoría y Estructura Sociales, México, Fondo de Cultura Económica, 1980, pp. 34-36).

2 L. A. Coser, Masters of Sociological Thought. Ideas in Historical and Social Context, S. Diego, Harcourt Brace Jovanovich, 1977, p. 330. 
Nature and the Social Order (1902), Social Organization (1909), Social Process (1918) y unos extractos del diario que llevó a lo largo de su vida publicados bajo el título Life and the Student (1927). Además, se publicó póstumamente, en 1930, un volumen titulado Sociological Theory and Social Research que contiene sus estudios tempranos sobre ecología social y otros trabajos de sus últimos años ${ }^{3}$.

En la plena euforia de democracia que estamos viviendo hoy, el texto en cuestión se vuelve más relevante, no sólo por la fe que expresa en esta forma de gobierno, por su visión optimista de las potencialidades de la democracia en general y de la norteamericana en particular, sino porque tiene un fino sentido analítico que pretende deslindar, dentro de la realidad social, lo que sucede por ser la implantación de la democracia en un país una novedad de lo que sucede porque lo que se implanta es una democracia. Cooley distingue en 1909 entre democracia y transición. Esta distinción es particularmente relevante en el caso español, pero también lo es para el análisis de esa otra nueva ola de democratización que parece hoy imparable, la de los llamados países de la Europa del Este. Con respecto a este último caso deberemos los científicos sociales estar atentos para ver hasta qué punto estos países forman un nuevo tipo de país. La pregunta que en el texto se formula sobre las relaciones entre cultura y sistema político es especialmente pertinente en este momento. Aunque en el texto la pregunta esté más referida, aunque no únicamente, a la alta cultura, podemos nosotros extenderla hacia las zonas de la cultura política y de la cultura en el sentido más amplio, antropológico, del término. Pensemos por un instante en la cuestión étnica reabierta en la Unión Soviética con la suavización de ciertos contro!es que está llevando a cabo la llamada Perestroika. ¿Hasta qué punto el sistema político y social soviético ha penetrado profundamente en la cultura profunda de los pueblos sometidos a él? ¿Se ha producido una cultura soviética en sentido profundo o ha sido una cultura más bien oficial? Las épocas de crisis y de llegada de a'go nuevo son épocas cuyo análisis es esencial para la ciencia social, porque enseñan mucho sobre el viejo sistema que se desintegra y sobre el nuevo que aún no está perfeccionado. Desde luego podemos ver que el nacimiento de la sociología como ciencia positiva de la Sociedad es consecuencia histórica del histórico paso de la tradición a la modernidad en los países europeos.

Cooley se plantea la importancia de la cultura básica, de ese substrato de valores y actitudes, de una población al margen de su forma de gobierno democrática. Se interesa por las diferencias entre el individualismo inglés y norteamericano y el colectivismo de Francia y otros países europeos. ¿No sería interesante volverse a plantear ahora la cuestión mientras observamos 
el desenvolvimiento democrático de esos países que están saliendo de un colectivismo extremo, aunque no sabemos si meramente oficial?

El texto es también de alto interés por su análisis de la situación de la alta cultura norteamericana allá en los comienzos de este siglo. Cooley piensa que la pobreza de la producción estética de aquellos momentos es un incidente debido a la rápida transición, precisamente. Piensa que es un incidente de desorganización. Pasa revista a una serie de condiciones de la vida social de la época que son barreras para el desarrollo de la producción estética: el comercialismo, la prisa, el ritmo de la vida, el hábito de la obra inacabada, el ruido, el desarrollo de un mercado inculto, del producto de mercado frente a la obra de arte... Estas condiciones de la vida serán en gran parte expresadas por el nuevo arte que se gestaría después. Una época nueva con un arte nuevo.

América, para Cooley, no recibe con la inmigración europea de los siglos pasados una gran cultura europea, porque ésta, para él, es una «cultura de clase» y las que emigran a América no son las clases más cultas. Pero en el nuevo orden piensa Cooley que América tiene sus ventajas, con respecto a Europa, pues está más completamente inmersa, al ser una realidad social nueva, en el nuevo orden de las cosas. Llega a decir que Norteamérica está más cerca del espíritu del orden que está viviendo y que esto tendrá su expresión, a su debido tiempo, en el orden del arte. Cooley está ya hablándonos de la importancia de la comercialización del arte, del mercado, de lo rápido e inacabado de la importancia de las instituciones filantrópicas de la posible traslación del centro del arte de Europa a Estados Unidos... Y está prediciendo esa expresión estética de ese mundo nuevo, que comenzará a ser evidente con la eclosión del arte norteamericano en la década de los treinta, bajo una importante influencia del muralismo mexicano, y la irrupción del expresionismo abstracto en la de los cuarenta, que, bajo una profunda influencia europea (por el hecho de la influencia ejercida por los clásicos del arte contemporáneo como Picasso, Kandinsky, Klee y Mondrian y la de los surrealistas como Miró, Ernst, Lam, Matta y Masson, y por el hecho de que varios de los protagonistas como Gorky, De Kooning, Yunkers, hubieran nacido en Europa), se consagra ya como un arte genuinamente norteamericano ${ }^{4}$.

\section{Alfonso PÉREZ-Agote}

4 Octavio Paz, Los privilegios de la vista. Arte de México, México, Fondo de Cultura Económica, 1987. Hemos utilizado, dentro de este libro, el ensayo titulado «EI precio y la significación», pp. 373-395. 